\title{
A Comparative Study of Social Media Users' Perception on the Malaysia Airlines Flight MH370 Incident in Mainland China and Malaysia
}

\author{
Wang Changsong, Chen Yiming, and Jamilah $\mathrm{Hj}$ Ahmad
}

\begin{abstract}
The transformation of online consumer's behavior is changing landscape of risk and crisis communications. How social media can be a beneficial tool for crisis management? How crisis managers respond to challenges posed by social media? These have become the focus on mobile communication studies. When Malaysia Airlines flight MH370 went missing, the flow of information experienced complexity uncertainty, and ambiguity in terms of information adequacy. The MH370 incident demonstrated an unprecedented international humanitarian response from the technology sector. The authors of this study found that this incident primarily involves attentions from audiences in Malaysia and China respectively. This study attempted to have a deep insight about online users' perceptions towards the portrait of this incident by the social media in Malaysia and China, and it discovered significant difference of user perception of active social media in these two countries. Social networking sites such as Facebook (in Malaysia), Weibo (in China) and Wechat (in China), become the public opinion field that illustrates sorts of openness and negotiation in Malaysia and China. This research, instead of conventional crisis communication approach, specifically examined active online users in both countries. The survey results contributed to mechanism of crisis communication for henceforth similar incident. The study illustrates different level of engagement with the content posted on social media in these two countries. There is no doubt that the portrait of Malaysia Airlines on social media in these two countries affected its organizational reputation. However, the participants from Malaysia and China showed a very average level of confidence to empower themselves to enhance dialog capacity among various stakeholders for this incident.
\end{abstract}

Index Terms-MH370 incident, social media, perception effect, crisis communication.

\section{INTRODUCTION}

Endless attention had been given to the missing Malaysia Airlines Flight MH370 in 2014. However, after two years, the possible debris only may get media's attention. In these two years, investigators from Malaysia and other affected countries used a part number found on the debris to link it to this missing Boeing 777. Unfortunately, in 2015 we witnessed that Malaysia Airlines practiced "plans for

Manuscript received January 18, 2017; revised May 20, 2017. This work was supported in part by USM Short-term Grant under Grant Nos. 304/PCOMM/6313269.

Wang Changsong is with Xiamen University Malaysia, Kuala Lumpur, Malaysia (e-mail: cswang@xmu.edu.my).

Chen Yiming is with the College of Journalism and Communication, Jinan University, Guangzhou, China (e-mail: jidayiming@163.com).

Jamilah Hj Ahmad is with the School of Communication, Universiti Sains Malaysia, Penang, Malaysia (e-mail: jahmad@usm.my). 'technically bankrupt' carrier include job cuts and fewer flight on some routes" [1]. However, for rebuilding trust, the efforts of deliberative procedures never would be enough to please existing and potential passengers. The massive audiences' perception toward the image of cooperate provides significant reference for crisis management. In these procedures, communication always acts its referential function to "to pass on new information to other" [2].

According to the survey conducted by the authors, $80 \%$ of Malaysian respondents choose social media as their main channel to receive information about MH370 incident; and in China $68 \%$ of respondents use social media to get information on this incident. The vast majority of respondents in Malaysia and China are using social media sites to engage in the web and catch up news. This has prompted social media sites to become major news source with various news stories there. Precisely, different social media landscapes in these two countries, and varied social media policies and regulations are likely to play an important role in determining how organizations "can optimize their crisis communication efforts by using social media platforms" [3].

Multiple studies (Herbst, 1998; Wendling, Radisch \& Jacobzone, 2013; DiStaso \& Bortree, 2014) have identified that social media use in crisis communication is complex and must be handled with care. The MH370 incident left so many uncertainty and complexity, but it led us to specifically discover how Chinese and Malaysian online users perceive the content related to this overwhelmingly high-impact tragedy respectively. Also, it is undeniable that "inaccurate information incorrectly changes meaning and alters our perceptions of reality" [4]. The difference of user perceptions might inspire crisis managers to re-look at approaches of rebuilding trust, and provide a better understanding of social media landscapes in China and Malaysia.

\section{LITERATURE REVIEW}

Researchers and scholars from Malaysia, China and other countries attempted to identify some key issues of dealing with crisis communication for this incident. Seven months after the Malaysia Airlines flight MH370 incident, Rohizah Bt. Halim, a lecturer from the School of Education and Modern Language, College of Arts and Science, Universiti Utara Malaysia, presented her research at the International Conference on Communication and Media (i-COME'14) held at Langkawi, Malaysia. The title was "From KL to Beijing: MH370, the Media and the Meaning of a Disaster". She examined the relevant news copies of two local 
newspapers. Rohizah (2014) concluded that the particulars of text media coverage on $\mathrm{MH} 370$ as a sociocultural event could be employed to understand how the media makes sense of a crisis/disaster/tragedy [5]. Her study explained the issues of uncertainty reporting. One year after this conference, in Kuala Lumpur, Taylor's University Lakeside Campus held the Fourth International SEARCH Conference with theme of crisis communication. The keynote speaker-Professor Ray Kemp from University of Wollongong-responded a question about the MH370 incident in the question and answer session at the end of his speech. Kemp (2015) brought forward that "roles of social media is very interesting, that is where rumours grow and the mainstream media actually picked up as a source... the experts on social media are not used to taking up roles to advise on crisis communication".

Actually, earlier than Rohizah's presentation, Wang Wanxi and another six co-authors published their quantitative research study in Mainland China in May 2014. Wang et al (2014) explored the impact of public perception and psychological anticipation by information dissemination at different phases of the crisis [6]. They found dramatic differences through time in perceptions of event clues and event characters. The same month, the American writer Nigel Cawthorne published his book "Flight MH370, The Mystery". His book made a number of incredible allegations (e.g., the airline was shot down by US-Thai strike fighters as part of a training drill that went horribly wrong). It attempted a most compelling explanation for the whodunit gripping the world.

The mystery of the crisis kept delivering possibilities and hopes against hopes. In September 2014, the Journal of Tianjin Normal University published an article entitled "Uncertain News and Unreliable Narration - A Journalism Study on the Missing Flight MH370". Liu Chang (2014) argued that the news coverage on MH370 [in China] indicated the arrival of 'uncertain news' [7]. However, we understand that the accuracy (or inaccuracy) of news is governed by several factors, such as access to information sources, possible existence of vested interests in misrepresenting events, and access to multiple news channels Some distortions may appear deliberate, while others may be inevitable. The brand "Malaysia Airlines" became a victim. We can infer from the foregoing, still provisional considerations, that if efforts are to succeed, they should redress 'uncertain news' and distortions. These also presuppose tangible evidence of willingness and determination to search for the missing plane and its passengers. On the other hand, social media, especially social networking sites such as Facebook (in Malaysia), and Weibo and Wechat (in China), become the public opinion field that illustrates a "sort of openness and negotiation" [8]. "Engagement in social media demands transparency" [9], however. Fictitious content still appeared to emanate from sources other than the actual point of origin in terms of causes of the crisis. For example, approximately fourteen thousand Wechat users clicked the posting entitled "Startling Inside Stories of Malaysia Airlines Missing Flight", although this specific post failed providing any reliable sources.

\section{OBJECTIVE OF THE STUDY}

The overall study objective is to compare social media users' perception on the Malaysia Airline flight MH370 incident in Mainland China and Malaysia respectively. Social media constitutes a central and powerful element of that omnipresent public perceptional process. When a crisis occurs, the public relies on media updates. Social media empowerment plays an integral part in this crisis communication.

This research aims to contribute to the identification of guiding principles for crisis communication, and in particular as regards the uses of social media in emergency services. The large-scale air disasters such as the Malaysia Airline flight MH370 incident have revealed the utility of Internet based social media tools such as Facebook, Wechat and Webo for risk and crisis communication. Organizations are trending toward using new media in their responses to crises. However, the types of new media communication tactics which organizations are using to mediate crisis responses determine the legitimacy, or illegitimacy, of the organizations' actions/expressions. At the same time, public opinion practices are "based in community in ways that are difficult to fathom in mass democratic societies of today" [10].

This research also aims to compare arenas of information exchange where dynamic and interactive flows of social-media data are in the hands of empowered individuals in Malaysia and China, who seek a more evidence-based participatory form of crisis communication. The MH370 incident demonstrated an unprecedented international humanitarian response from the technology sector. A global community of civilians from multiple countries with a unified purpose came to the aid of grief stricken, mostly Chinese and Malaysian, people. We precisely notice that public expectations and roles are changing in terms of the desire for increased transparency of information, in the spirit of open government, and participation in information gathering, sharing and verification.

\section{HYPOTHESIS}

The hypothesis in this section designates suggested explanations for phenomena relevant to the MH370 flight incident.

\section{A. Hypothesis 1}

It is hypothesized that the technical and social knowledge to work with social media represents a steep learning curve for crisis managers who are used to working with traditional new media. We understand social media and social media apps are more important tools of communication than traditional new media. As the magnitude of Internet and smart phone users increases, we cannot ignore that social media play "a pivotal role in changing the public understanding of control, freedom, and creativity" [11].

\section{B. Hypothesis 2}

It is hypothesized that there is a significant relationship between empowerment of social media and effectiveness of crisis communication (mitigating potential reputational damage). Crowd sourcing crisis relevant information from social media streams is considered a key area where technological innovation can be valuable for emergency 
services and authorities in charge.

\section{Hypothesis 3}

It is hypothesized that there are different arenas of information exchange where dynamic and interactive flows of social-media data circulate freely among empowered individuals in Malaysia and Mainland China while these individuals seek a more evidence-based participatory form of crisis communication. It will be argued that, while social media has empowered informal partnerships that enhance dialog capacity among various stakeholders, major challenges can be identified.

\section{Methodology}

This study aims to make a valuable contribution by synthesizing current research and identifying areas for investigation for each aspect of the survey process. This method will be valuable in providing this research with an empirically-based understanding of the relationships between crisis communication and social media in China and Malaysia. Two hundred questionnaires had been collected from respondents in China and Malaysia respectively. The response rate was $100 \%$ and 400 questionnaires were available. Survey methodology applied in this research investigates the behaviour of social media users, reading preference, and so on. The information that has been collected represents the key concept of the research. The section of finding and discussion will illustrate the variables and concepts throughout the analysis.

\section{FINDINGS AND DISCUSSION}

Social media empowers people in digital production practices [12]. However, social media sites have introduced new issues regarding the accuracy, originality and reproducibility of digital content that are particularly difficult to address, and they have blurred the lines from producer of information to audiences to a far greater extent than was the case for previous media forms. Simon Kemp's 2016 Digital Yearbook particularly looked at the following four major populations-Internet users, active social media users, unique mobile users, and active mobile social users (Kemp, 2016)-which represent significant indictors to measure different behavior preferences of online users at present. His research revealed that 1,379 million digital online users in China, which indicated China's level of urbanisation had reached $57 \%$, and $95 \%$ of them own mobile connection. Among them there are 653 million active social media users. In Malaysia, there are 18 million active social media users, which take up 59\% of online user population [13].

\section{A. Survey Respondents in China and Malaysia}

From 2015 to 2016 the authors of the study conducted a survey in China and Malaysia respectively. There remain some differences between the individual's self-defined category of online users and actual behavior. The survey had been discovered that $54.5 \%$ of respondents from China saw themselves as active Internet users, and only $15 \%$ of them believed they were active social media users. Nevertheless, the survey had identified that yet there was a contradiction between frequencies of social media usage and self-defining since $89 \%$ of all respondents used social media more than three times a day. The survey conducted in Malaysia also revealed that only $25 \%$ of Malaysian respondents considered themselves as active social media users, and $13.5 \%$ of respondents categorized themselves into groups of mobile social media users, however, actually $85.5 \%$ of them belonged to the active interval according to their frequencies of social media usage. Most of the time, individuals unconsciously access the content and they do not really calculate the frequency as social media apps empowers end users with instant access to resources and content through a single click. For example, Weibo provides news feed on the lock screen, which allows users to be aware of the news instantly. Obviously, we've been exposed to dissemination of the contents every second thanks to its "ontological qualities" [14]. The news feed appeared on the users' mobile screen encompasses important issues regarding social life, urban ecology, state news and so on.

Malaysia is a multi-ethnic, multicultural, and multilingual society, and many ethnic groups in Malaysia maintain separate cultural identities. But the survey showed that the result is not affected by ethnic factors. There is no any obvious indication that frequency of social media site use is affected by ethnic factors. Some of the survey questions, however, illustrated different perception affected by ethnic factors. It will be further discussed in the next section. The largest age range of respondents in Malaysia accounted for $81.5 \%$ is 18 to 30 years old. The second largest age range is 31 to 40 years old, which make up $13 \%$. The rest $5.5 \%$ respondents are 40 years and above. Interestingly, in China most respondents are from the age groups of 18-30 and 31-40 years old. They make up $42.5 \%$ and $41.5 \%$ respectively.

\section{B. Perception Traits of social Media Users in China and Malaysia}

This research intended to compare arenas of information exchange where dynamic and interactive flows of social-media data are in the hands of empowered individuals in Malaysia and China, who seek a more evidence-based participatory form of crisis communication. The survey had discovered that social media in China is not the most used media for users to access information about MH370 incident. Online news portal is the most popular form. However, Malaysian respondents prefer using social media to online news portal and television while they seek updates of the MH370 incident. The charts (see Fig. 1) below illustrate $80 \%$ of Malaysian respondents choose social media while $68 \%$ of Chinese respondents do so. Since 1990s, Chinese people frequently use news portals sites as these sites have been distinguish in their news presentation. For example, as one of the biggest three news portal site in China, NetEase makes it news perspectives often different from those of mainstream traditional media. $\mathrm{Wu}$ (2013) pointed out that "portal websites in China have become one of the most influential media in China, particularly their influence over the youth population" [15]. Additionally, television is another popular 
media in China. In China Turned On: Television, Reform and Resistance, Lull (2013) mentioned, "television had become the preferred news medium of urban residents" [16]. Just like many societies all over the world, people in China rely on television for news.

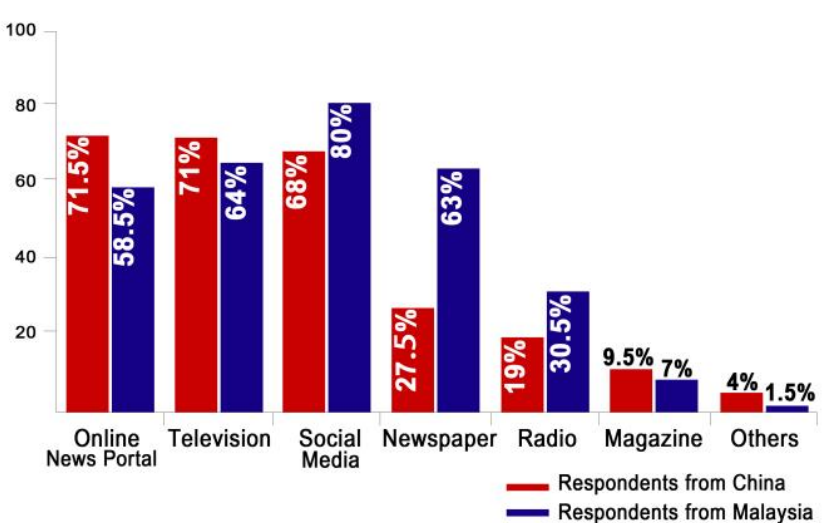

Fig. 1. Respondents' choices of media channel to receive updates of MH370 incident in China and Malaysia.

However, respondents from Malaysia showed their different choice of media for news. Numbers of television broadcast stations in Malaysia are significantly less than the ones in China. There are only eight public television channels owned by three major stations, which are Radio Televisyen Malaysia (RTM), Media Prima, and Al Hijrah Media Corporation respectively. News programmes produced by these three companies embrace languages of Malay, English, Chinese, and Tamil for the needs of different ethnic populations. $80 \%$ of respondents in Malaysia rely on social media more than other media source for news about the MH370 incident. Although in China, people more rely on online news portal sites and television, $68 \%$ of respondents choose to use social media as the main media channel to receive updates of $\mathrm{MH} 370$ incident. The number of the respondents is just slightly lower the viewers of news portal sits and television. In a word, social media offer great potential for mobilising people for participation in this incident.

The other difference between respondents from China and Malaysia is their attention to different news content although it is associated with greater factual knowledge of that content. Most of Malaysian respondents concern on current situation of MH370 incident through social media, but most of Chinese respondents pay attention to information on flight's conspiracy theories. The charts (see Fig. 2) show that respondents from both countries pay less attention to emotion of lost passengers' family.

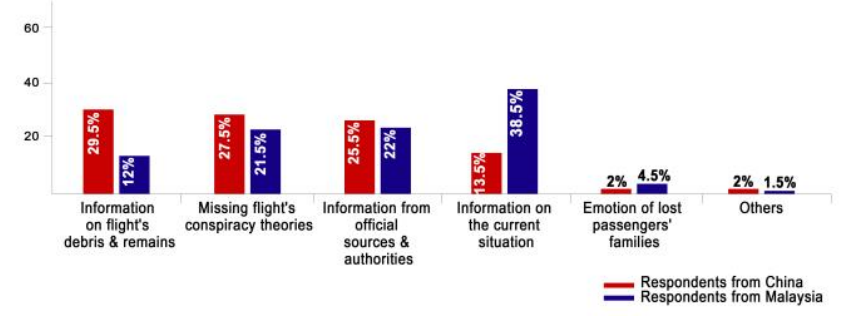

Fig. 2. The specific content posted on social media respondents mostly paid attention to.
During the MH370 incident Malaysia has highest level of engaged social media users, but after the incident Malaysia has biggest number of users do not care what the incident goes on. The charts (see Fig. 3) below show $17.5 \%$ of Malaysian respondents never engaged on social media for any updates after the incident. The authors also noticed that $39 \%$ of Chinese respondents follow the relevant content less than 1 time after the incident.

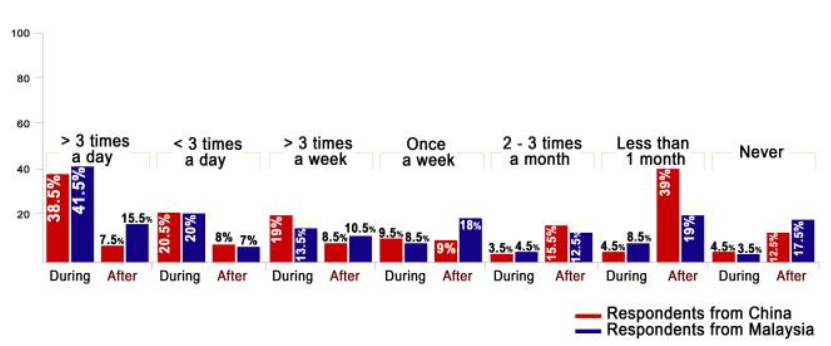

Fig. 3. Comparison of frequency of users' engagement on social media during and after MH370 incident.

The popular social networking sites in Malaysia and China are very different from each other. However, one social media site attracts most of users in Malaysia and China respectively. The figure (see Fig. 4 and Fig. 5) below shows Facebook is the leading social media site in Malaysia, and Wechat is the most popular site in China. However, the survey discovered that Sina Weibo in China is the most trusted site where users get information of the MH370 incident. $61.5 \%$ of respondents trust Sina Weibo, and $55.5 \%$ of them think Wechat is effective in addressing crisis of MH370. Although Wechat has biggest use population, it is just the second most trusted social media site. In Malaysia, $75.5 \%$ of the respondents believe Facebook is effective in addressing the MH370 incident, and Google+ is the second most trusted site. The Internet and online social networking sites have begun to merge the concepts of interactive communication and mass media [17]. These sites present unique gratification factors. The survey illustrates levels of trust of popular social media sites in these two countries. These would be helpful for crisis managers to consider proper channels to disclose information.

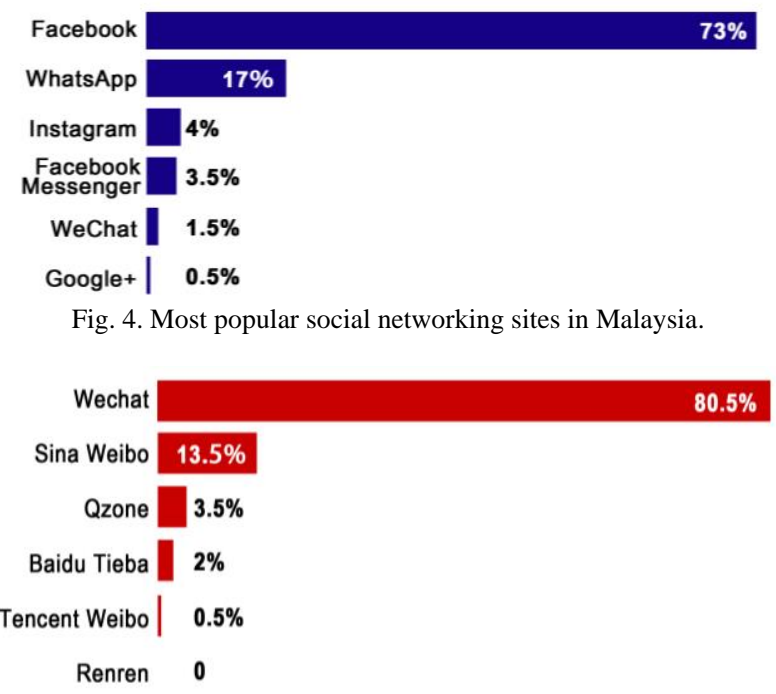

Fig. 5. Most popular social networking sites in China. 
These social networking sites empower and connect individuals in ways that crisis incident is expected to be addressed intergovernmental relations during "the four phases of the disaster (i.e., mitigation, preparedness, response, and recovery)" [18]. It also reveals the weakness of social media sites while they deal with crisis incidents as the survey respondents from both countries highly agree that reliability of the news on social media is low. The charts (see Fig. 6) below illustrate $62 \%$ of Malaysian respondents and $44 \%$ of Chinese respondents question its reliability. $39.5 \%$ of Malaysian respondents and $38 \%$ of Chinese respondents prefer receiving news from traditional news sources such as newspaper and television. People frequently use social media sites, but at the same time question the reliability of these sites. The relationship lies between information provider and interpreter on social media is considered an informal form. For instance, Facebook networks do not really describe the flow of information. Instead, they show paths of mutual awareness [19].

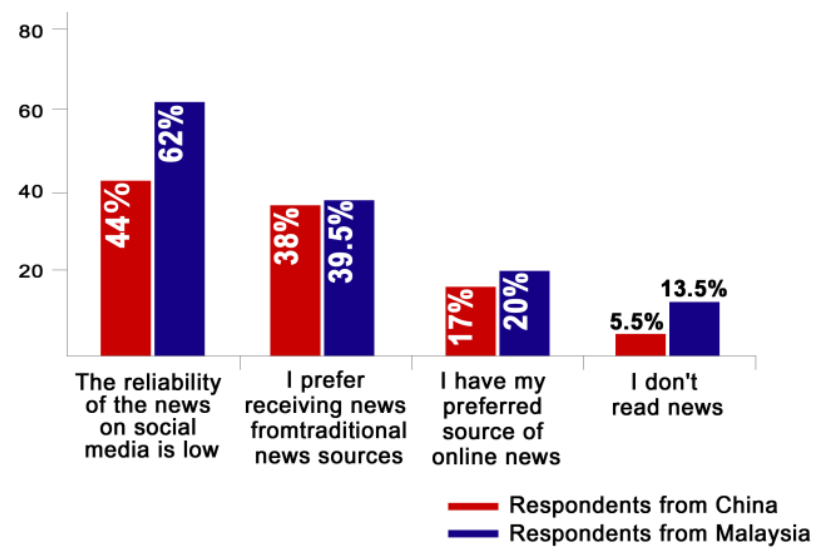

Fig. 6. The reasons preventing respondents from using social media for updates of MH370.

\section{Perception's Effect}

Very less proportion of Chinese respondents flew with Malaysia Airlines, and only $15 \%$ of them did fly Malaysia Airlines flights before. Interestingly, after the incident, more respondents showed their interest to choose Malaysia Airlines services. Among them, there are $31.25 \%$ male respondents, and $38.46 \%$ female respondents. The same goes to Malaysian respondents. There are $71.29 \%$ male respondents and $61.62 \%$ female respondents are willing to fly with Malaysia Airlines flights after the incident, although $54.6 \%$ male and $47.47 \%$ female respondents take flights operated by Malaysia Airlines. This paper will not discuss the reason behind, but these figures provide crisis managers a good reference to plan their strategies of crisis communication after the incident/disaster.

If we look at the proportion of respondents who show willingness to take flights operated by Malaysia Airlines according to their income, we found that most people are in the category of comfortably-off (Xiao Kang in Chinese) individuals with the annual income of 80,000-300,000 Chinese Yuan. The largest proportion of respondents who fly with Malaysia Airlines is also in the same income category. It makes up $19.35 \%$ of all Chinese respondents. $47.92 \%$ of the respondents from this category showed high willingness to take flights operated by Malaysia Airlines for their future trips. In Malaysia, $90.32 \%$ of the individuals with monthly income of 4,000 Malaysia ringgit and above have flown with Malaysia Airlines. The second largest proportion is the group with monthly income of 3,000 to 3999 Malaysian ringgit. It makes up $73.3 \%$ of this group. However, $87.1 \%$ of the respondents from the group with monthly income of 4,000 Malaysia ringgit and above are still willing to fly with Malaysia Airlines. 93.33\% of the respondents from the group with monthly income of 3,000 to 3,999 Malaysian ringgit express their willingness to take flights by Malaysia Airlines.

The data mentioned above illustrate the support towards Malaysia Airlines, but there are a number of respondents believe that portrayal of MH370 incidents by social media affect their perceptions. $49.5 \%$ of Chinese respondents agree it affects his/her decision-making of choosing Malaysia Airlines, and $42.5 \%$ of them show their neutral stand. Only $8 \%$ of them disagree it does not affect his/her choice. In Malaysia, $34.5 \%$ of respondents agree it affects his/her choice of flights operated by Malaysia Airlines. 37\% of them take the neutral stand, and $28.5 \%$ of the respondents do not see it affects their choice of choosing Malaysia Airlines.

The number of global Internet users is expected to increase [20]. With the Internet connection, people are connected in some ways. We understand that "the primary objective of social media is to facilitate the communication and interaction between users and allowing them to edit and share content, social media platform are designed to facilitate the exchange of information" [21]. Kirkham and Muthaly (2015) stated, "Both Malaysia Airlines and the government have used the social media extensively, though not always to the greatest effect" (p. 66). The Malaysian news agent-Free Malaysia Today, on the $9^{\text {th }}$ September 2016, published a report which shows the appeal to have "... International Civil Aviation Organisation to step in and make Malaysia more accountable investigation" [22]. The word 'passive' has been labelled in a number of publications when they investigate the incident from various perspectives.

\section{CONCLUSION}

The comparative study of social media users' perception on the Malaysia Airline's MH370 incident in Mainland China and Malaysia showed us different perception's effect in these two countries. The information highly caught attention among social media users represents the arena to which crisis managers should pay more attention. Respondents from China and Malaysia demonstrated their different level of trust towards the airline company after the incident, different understanding of impact of the crisis on the company itself, and also different perspective to examine the content shared and discussed on social media.

In general, social media may be regarded as an umbrella term that covers many kinds of user-based platforms in these two countries. The availability and reliability of information play an important role in reducing ambiguity for a variety of reasons. But residents in these countries have their own preference in terms of social networking sites. Facebook, which is the most popular social media site in Malaysia, is still banned in China, but WeChat and Weibo provide them similar platform to dig up the fact. 


\section{REFERENCES}

[1] Malaysia Airlines lays off 6,000 employees. (Jane 1, 2015). Al Jazeera. [Online]. Available: http://www.aljazeera.com/news/2015/ 06/malaysia-airlines-lays-6000-employees-150601105838604.html

[2] W. Leeds-Hurwitz, Communication in Everyday Life: A Social Interpretation, Norwood: Ablex Publishing, 1992, ch. 6, pp. 129-148.

[3] A. Dudo and L. A. Kahlor, Strategic Communication: New Agendas in Communication, New York \& Oxon: Routledge, 2016, ch. 9.

[4] R. Telofski, Living on a Meme: How Anti-Corporate Activists Bend the Truth, and You, to Get What They Want, Bloomington: iUniverse, 2012 , ch. 8, pp. 123-164.

[5] B. H. Rohizah, "From KL to Beijing: MH370, the media and the meaning of a disaster," International Conference on Communication and Media, pp. 171-177, 2014.

[6] W. X. Wang et al., "Dissemination of information influence population cognition and psychological expectations about the event of the missing Malaysia Airlines MH370 at different stages," Journal of Third Military Medical University, vol. 36, no. 12, pp. 1307-1311, 2014.

[7] C. Liu, "Uncertain news and unreliable narration-A journalism study on the missing flight MH370," Journal of Tianjin Normal University (Social Science), vol. 4, pp. 42-46, 2014.

[8] S. Herbst, Reading Public Opinion: How Political Actors View the Democratic Process, Chicago and London: The University of Chicago Press, 1998, ch. 1.

[9] M. W. DiStaso and D. S. Bortree, Ethical Practice of Social Media in Public Relations, New York: Routledge, 2014, ch. 1.

[10] A. J. Berinsky, New Directions in Public Opinion, New York: Routledge, 2012, ch. 1.

[11] Y. Benkler, The Wealth of Networks: How Social Production Transforms Markets and Freedom, New Haven: Yale University Press, 2006, ch. 1.

[12] R. Mansell and P. H. Ang, The International Encyclopedia of Digital Communication and Society, Hoboken: Wiley-Blackwell, 2015, ch. 1, pp. 1014- 1026.

[13] S. Kemp. 2016 digital yearbook: We are social's compendium of global digital, social, and mobile data, trends, and statistics [PowerPoint Slides]. [Online]. Available: http://www.slideshare.net/wearesocialsg/digital-in-2016, 2016.

[14] V. Eisenlauer, A Critical Hypertext Analysis of Social Media: The True Colours of Facebook, London and New York: Bloomsbury Academic, 2013, ch. 2, pp. 99-138.

[15] M. Wu, P. Jakubowicz, and C. Cao, Internet Mercenaries and Viral Marketing: The Case of Chinese Social Media, Hershey: IGI Global, 2013, ch. 2, pp. 24-64.

[16] J. Lull, China Turned On: Television, Reform and Resistance, Oxon: Routledge, 2013, ch. 7.

[17] A. B. Albarran, The Social Media Industries, New York and London: Rouledge, 2013, pp. 166-190.

[18] A. C. Henderson, "The Critical Role of Street-Level Bureaucrats in Disaster and Crisis Response," in Handbook of Critical Incident Analysis, R. W. Schwester, Ed. New York \& Oxon: Routledge, 2014 pp. 210-245.
[19] D. Hansen, B. Shneiderman, and M. A. Smith, Analyzing Social Media Networks with NodeXL: Insights from a Connected World, Burlington: Elsevier, 2011, ch. 11, pp. 165-180.

[20] W. M. Pride, R. J. Hudges, and J. R. Kapoor, Foundations of Business, Standford: Cengage Learning, 2015, ch. 14, pp. 394-425.

[21] FMT Reporters. Malaysia has bungled MH370 search, says aviation writer. Free Malaysia Today. [Online]. Available: http://www.msn.com/en-my/news/world/malaysia-has-bungled-mh37 0 -search-says-aviation-writer/ar-AAiCZ62?li=BBr8Hn

[22] D. Kamil and C. D. Derya, Political Scandal, Corruption, and Legitimacy in the Age of Social Media, Hershey: IGI Global, 2016, ch. 3, pp. 51-50.

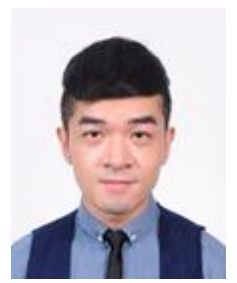

Wang Changsong is currently an assistant professor of Xiamen University Malaysia. He obtained his bachelor of arts on advertising from Suzhou University, Suzhou, China, master of Communication on screen studies, and doctor of philosophy on film and broadcasting from Universiti Sains Malaysia, Penang, Malaysia.

He was a lecturer at the School of Communication, Universiti Sains Malaysia. Currently he is the expert member of Asia and Chinese language cinema research center of Beijing Normal University, Program Coordinator of Journalism Programme at Xiamen University Malaysia and the founding director of Center for ASEAN and Chinese Screen Studies of Xiamen University Malaysia.

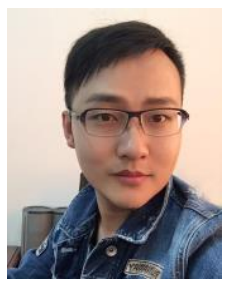

Chen Yiming is currently an assistant professor of the College of Journalism and Communication, Jinan University, Guangzhou, China. He obtained his bachelor degree on broadcasting and hosting art from Zhejiang University of Media and Communications, and master of arts in media studies from Coventry University, United Kindgdom.

$\mathrm{He}$ is now doing his double Ph.D research at Uppsala University (Sweden) and Free University of Brussels (VUB, Belgium). He is also director of bachelor program of broadcasting and hosting arts of Jinan University.

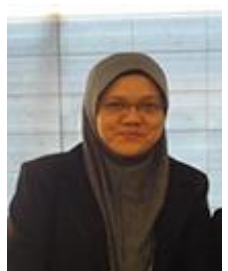

Jamilah Hj Ahmad is a professor of the School of Communication, Universiti Sains Malaysia. She obtained her bachelor degree of arts from Universiti Teknologi MARA (UiTM), Malaysia, master of arts from The University of Manchester, United Kingdom, and doctor of philosophy from Deakin University, Australia. She was the dean of the School of Communication, Universiti Sains Malaysia. 